\title{
TESTING OF SOIL IMPROVEMENT BELOW A HALL FLOOR
}

\author{
Monika Súlovská*, Peter TurČek, Zuzana Štefunková \\ STU Bratislava, Faculty of Civil Engineering, Radlinského 11, Bratislava, Slovakia \\ * corresponding author: monika.sulovska@stuba.sk
}

\begin{abstract}
Construction of a hall situated in North-West Slovakia was prepared in winter. After finishing an elementary ground adaptation in February there were extreme weather conditions: the precipitation exceeded by over $300 \%$ the normal long term measured amount. This indisposition of climate led to a stopping of the construction work. Checks on the required quality of the base course using static load tests showed a failure in performance of compaction. The sampling and laboratory testing of the original and the improved soils are discussed in the paper.
\end{abstract}

KEYWORDS: Quality control, base course, laboratory analysis, consolidation test, cement content.

\section{INTRODUCTION}

The required intensity of deadlines for finishing the construction regardless of limiting conditions (e.g. climatic, occurrence of soils with low bearing capacity) conduced on a good number of occasions to improvement efforts on the base course. These are usually similar technologies to those used in road construction. Among the most common technologies there is included adding a certain percentage of lime or cement to fine-grained soils6 (so-called soil stabilization). Mixing cement with soil and compaction reduces the compressibility of the treated soil. Subsequent quality control of any improvement is mostly done by static load test.

The underlying layers of the future floors were simply improved within the rainy weather and were not protected. The adverse weather situation caused the suspension of work. Checking the quality of the underlying layers using static load tests after a week of completion of the stabilization showed a failure to satisfy the required improvement. It was necessary to immediately resolve the situation and help meet deadlines. Consequently soil was taken from the unsatisfactory area of the hall and then a check was made on the properties of both treated and untreated layers by laboratory tests.

\section{LABORATORY TESTS}

On the construction site of the hall there were removed undisturbed soil samples improved by cement, but also the original soil without improvement by cement. On the original soil samples there were firstly detected the basic descriptive soil characteristics. Based on STN 721001 [1] there was soil classified as firm clay with low plasticity (F6 - CL). The original moisture of the soil was more than $20 \%$. The moisture of the improved soil with cement did not differ from the moisture of the original soil.

To determine the optimum moisture of soil for compaction there was used the Proctor test (see
Fig. 11. The optimum moisture of the tested soil was determined $w_{\text {opt }}=15.2 \%$. This corresponds to the maximum dry density of soil $\rho_{\max }=1.768 \mathrm{~g} / \mathrm{cm}^{3}$. The collected samples had significantly higher moisture content than its optimal moisture.

\subsection{Oedometric tests on Undisturbed SOIL SAMPLES}

Compressibility testing on the oedometer was made to the original and also the improved soil. At improvement there was added into the soil $5 \%$ of cement. The results of average deformation characteristics of original and improved soil are collected in Table 1

On the basis of laboratory results there can be determined for the improved soil the following increases in deformation characteristics:

- $\quad$ at stresses in soil $\sigma \leq 50 \mathrm{kPa}$

$$
\frac{E_{\text {oed } \mathrm{stab}}}{E_{\text {oed } n o t}}=\frac{32.25}{5.10}=6.32
$$

- $\quad$ at stresses in soil $50 \leq \sigma \leq 100 \mathrm{kPa}$

$$
\frac{E_{\text {oed } s t a b}}{E_{\text {oed } n o t}}=\frac{14.13}{5.70}=2.47
$$

- $\quad$ at stresses in soil $100 \leq \sigma \leq 200 \mathrm{kPa}$

$$
\frac{E_{\text {oed } s t a b}}{E_{\text {oed } n o t}}=\frac{15.19}{9.62}=1.58
$$

Based on the stress range of its own weight and the expected load from buildings, the improvement of soil after adding cement was 1.5 to 2 times. The recommended values in the deformation modulus of improved soil should not exceed the value $E_{\text {oed }}=$ $14 \mathrm{MPa}$.

\subsection{Compression tests OF SOIL Without IMPROVEMENT AT COMPACTION AFTER THE PROCTOR STANDARD}

Artificially prepared samples of soil compacted after Proctor standard were tested in the oedometer. The 


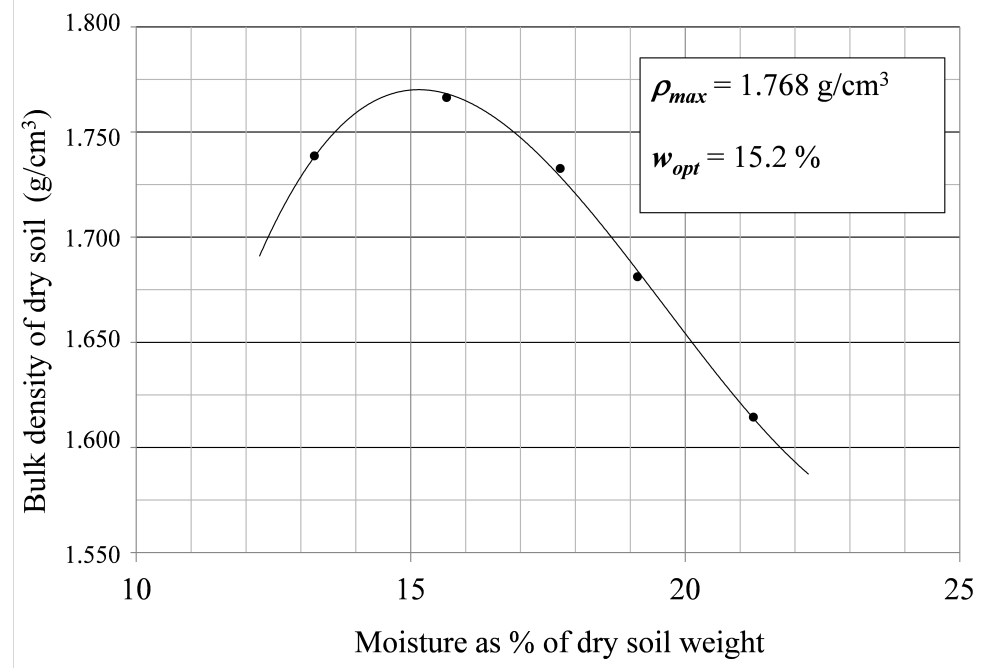

FiguRE 1. Determination of the maximum bulk density versus optimum moisture.

\begin{tabular}{|c|c|c|c|c|}
\hline \multirow{3}{*}{$\begin{array}{c}\text { Normal stresses } \\
\sigma_{1}-\sigma_{2} \\
(\mathrm{MPa})\end{array}$} & \multicolumn{4}{|c|}{ Average modulus } \\
\hline & \multicolumn{2}{|c|}{ Improved soil } & \multicolumn{2}{|c|}{ Primary soil } \\
\hline & $E_{\text {oed }}(\mathrm{MPa})$ & $E_{\text {def }}(\mathrm{MPa})$ & $E_{\text {oed }}(\mathrm{MPa})$ & $E_{\text {def }}(\mathrm{MPa})$ \\
\hline $0.010-0.025$ & 35.73 & 16.79 & 3.84 & 1.81 \\
\hline $0.025-0.050$ & 32.25 & 15.16 & 5.10 & 2.40 \\
\hline $0.050-0.100$ & 14.13 & 6.64 & 5.70 & 2.68 \\
\hline $0.100-0.200$ & 15.19 & 7.14 & 9.62 & 4.52 \\
\hline
\end{tabular}

TABLE 1. Deformation modulus of soils determined from compression tests.

resulting average oedometer modulus corresponding to different moistures of tested soils are evaluated in Table 2,

Effects of changes in soil moisture on the oedometric modulus are shown in Fig. 2. The plasticity index of soil was $I_{P}=10 \%$ (liquid limit $w_{L}=30.5 \%$ and plasticity limit $\left.w_{P}=20.5 \%\right)$. Until the soil was in natural conditions and firm consistency, there were found very small values of deformation characteristics of tested soil to all extents of normal stresses. Increasing the soil stiffness (higher values of Eoed) was possible by observing a decreasing of soil moisture below $17 \%$. The consistency of soil at such moisture was $I_{C}=1.4$. Decreasing the moisture below $17 \%$ significantly increases the oedometric modulus of the soil.

Analysis of Fig. 2 taking into account Fig. 1 can be stated as:

- $\quad$ Exceeding the optimum moisture $w_{\text {opt }}$ occurred in samples loaded by normal stress of $50 \mathrm{kPa}$ with rapid decreasing of $E_{\text {oed }}$.

- With an increasing of moisture there was observed a significant decreasing of $E_{\text {oed }}$ at lower normal stress $(<50 \mathrm{kPa})-$ more than 5 -times. Exceeding the value of normal stress $50 \mathrm{kPa}$ and with increasing the moisture there was found a decreasing of $E_{\text {oed }}$ approximately 3.5 times.

In the test range of normal stress $E_{\text {oed }}$ was significantly affected by moisture. In Fig. 3 there is shown the relationship between deformation characteristics and normal stresses of soil at various initial moistures of the soil. Also in this evaluation it was proved the moisture was around $17 \%$ than the limit. At lower moisture there were detected significantly different deformation parameters, especially at normal stress to $50 \mathrm{kPa}$.

\subsection{IMPROVING THE SOIL CHARACTERISTICS BY ADDING CEMENT}

At natural moisture of soil $20 \%$ of collected samples had values of deformation modulus of the original soil which were very low. The addition of cement decreased soil moisture, whilst increasing the deformation parameters was not sufficient.

Very interesting results were obtained from evaluation of the effect of the $5 \%$ addition of cement (see Fig. 4). At lower humidity than $20.5 \%$ (on a stiff consistency) there was observed a significant effect of the cement. At the same time, the effect of improvement increases with lower levels of normal stress. Adding $5 \%$ of cement at optimal soil moisture brought a 2-3 times increase of $E_{\text {oed }}$ compared to unimproved soil. Exceeding soil moisture $w=20.5 \%$ the soil fell into firm consistency and the impact effect of the cement was shown to be very low to negligible. Cement added to the soil with natural moisture, got between 19 to $21 \%$, extracting a portion of water by hydration. This will inevitably reduce soil moisture itself. It can be assumed that the excess of the initial 


\begin{tabular}{|c|c|c|c|c|c|}
\hline Normal stresses & \multicolumn{5}{|c|}{ Oedometric modulus $E_{\text {oed }}(\mathrm{MPa})$} \\
\cline { 2 - 6 } $\begin{array}{c}\sigma_{1}-\sigma_{2} \\
(\mathrm{MPa})\end{array}$ & $w=13.25 \%$ & $w=15.65 \%$ & $w=17.73 \%$ & $w=19.13 \%$ & $w=21.24 \%$ \\
\cline { 2 - 6 } & $E_{\text {oed }}$ & $E_{\text {oed }}$ & $E_{\text {oed }}$ & $E_{\text {oed }}$ & $E_{\text {oed }}$ \\
\hline $0.010-0.025$ & 23.05 & 18.31 & 6.66 & 5.35 & 3.18 \\
\hline $0.025-0.050$ & 21.72 & 16.61 & 4.72 & 2.42 & 2.22 \\
\hline $0.050-0.100$ & 13.36 & 9.40 & 5.49 & 3.20 & 3.04 \\
\hline $0.100-0.200$ & 13.36 & 9.66 & 7.44 & 5.12 & 4.98 \\
\hline
\end{tabular}

TABLE 2. Average oedometric modulus of tested soils at various moistures.

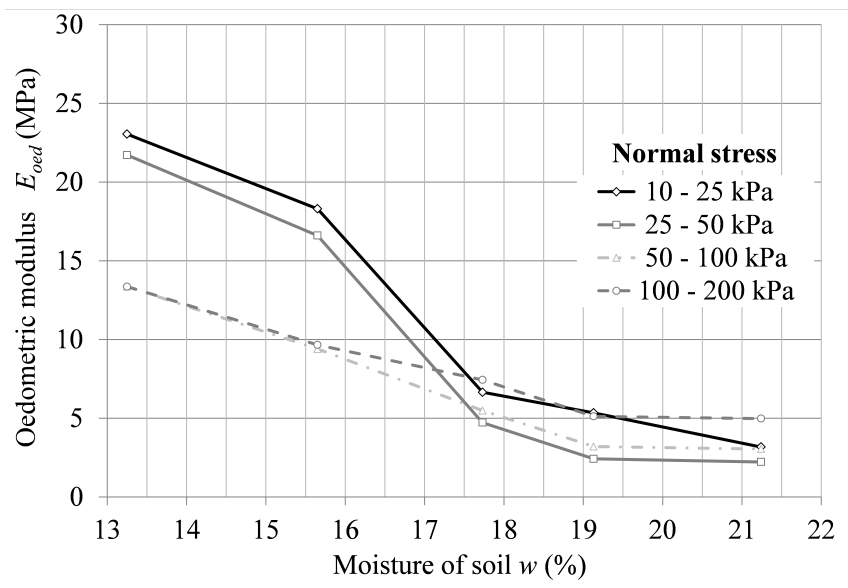

FIGURE 2. Relationship between moisture of tested soil and oedometric modulus.

moisture content in excess of the $w_{\text {opt }}+5 \%$ there is to be expected a significant decrease in the effect of stabilization.

\section{The quality ASSESSMEnt And The CEMENT CONTENT IN THE SOIL}

Cement and its contents were independently tested in the stabilized soil. Laboratory tests of the physicalmechanical properties of cement were carried out and supplemented by X-ray and DTA analysis. Stabilized soil was investigated by DTA and also X-ray analysis.

Tested cement was used to stabilize the soil at the construction site. The studied properties and the results derived are as follows:

- $\quad$ After 28 days, the compressive strength reached 48.3 MPa. This value is in accordance with the requirements of the class of cement $42.5 \mathrm{MPa}$ according to EN 197-1.

- $\quad$ Bulk density with a timed deposit of test samples slightly increased. After 28 days, the bulk density reached a value around $2190 \mathrm{~kg} / \mathrm{m}^{3}$, which corresponded with standard values.

- $\quad$ By testing the cement slurry, it was found that the cement needs to reach a slurry of normal density of $32 \%$ water.

- The initial set of cement slurry observed after 195 minutes, in which it fulfilled the limit set by the standard. Final set occurred after 250 minutes.
- $\quad$ Soundness of the testing cement went to $6.0 \mathrm{~mm}$, which met the standard set limit of $10 \mathrm{~mm}$.

- Bulk density of fresh cement mortar was $2160 \mathrm{~kg} / \mathrm{m}^{3}$. All testing samples had low scatter from the average.

- $\quad$ X-ray analysis showed the incidence of cement clinker minerals as Alite - $\mathrm{C}_{3} \mathrm{~S}$ (Tricalcium silicate), Belite - $\mathrm{C}_{2} \mathrm{~S}$ (Dicalcium silicate), Brownmillerite - $\mathrm{C}_{4} \mathrm{AF}$ (Tetracalciumaluminoferrite), $\mathrm{C}_{3} \mathrm{~A}$ (Tricalcium aluminate) and gypsum setting regulator $\left(\mathrm{CaSO}_{4} \cdot 2 \mathrm{H}_{2} \mathrm{O}\right)$. Furthermore, there occurred Silica $\left(\mathrm{SiO}_{2}\right)$, Calcite $\left(\mathrm{CaCO}_{3}\right)$ and Portlandite $\mathrm{Ca}(\mathrm{OH})_{2}$. According to this composition it can be assumed that this was Portlandcomposite cement CEM II.

Tests of the stabilized soil by method X-ray and DTA showed that samples taken from the hall after the defective area of the static load tests contained less than $2 \%$ of cement. By applying the same method to artificially prepared samples there was found good correspondence with the percentage of added cement.

\section{Conclusion}

Based on the compressibility tests on the stabilized soil it is clear that the high moisture of the soil after the rainy season had not reached sufficiently an increasing of the soil parameters. They showed two reasons for failure to satisfy the criteria required for static load testing. The first reason was lower cement content as determined by the project. Instead of $5 \%$ of the cement which was in samples taken from the 


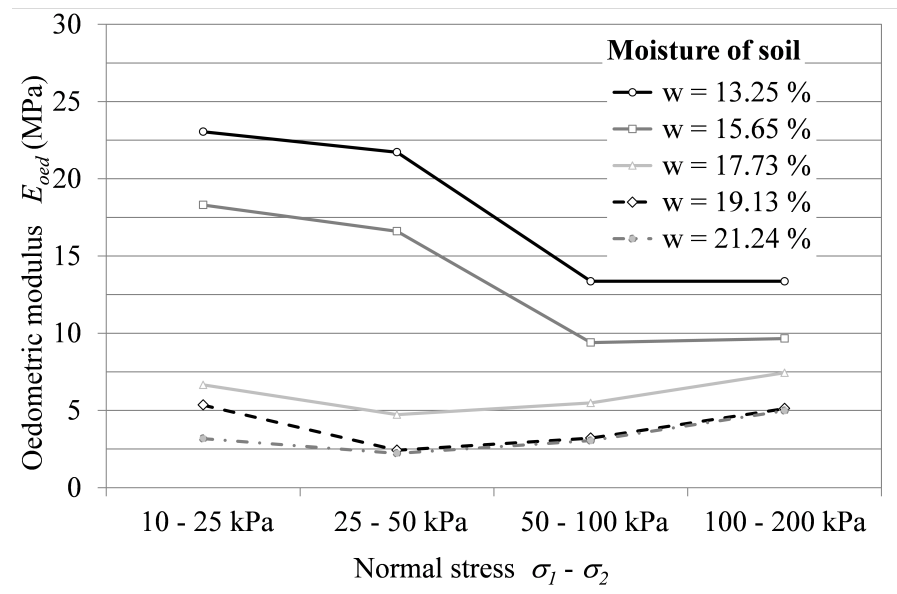

FiguRE 3. Dependence of normal stress and moisture on deformation characteristics of soil.

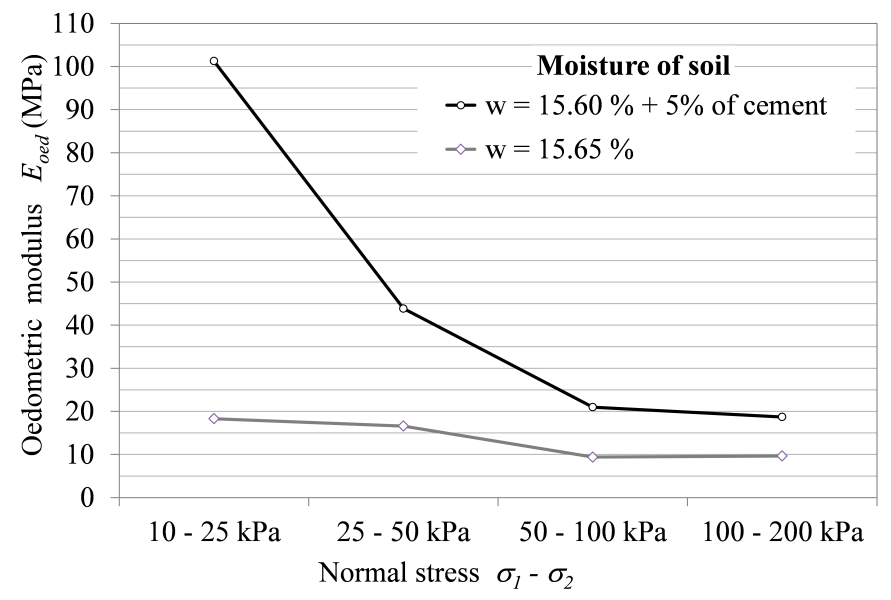

Figure 4. Influence of addition $5 \%$ cement into the soil on $E_{\text {oed }}$ at optimum moisture.

subgrade in the construction site there was found only a cement content in the range of 1 to $2 \%$. Significant precipitation caused the natural soil moisture to exceed $20 \%$. Laboratory experiments have shown that at such a level of moisture in the not improved original soil the deformation properties of soil are very low. Mixed cement decreased soil moisture, but it reflected only a small increase of $E_{\text {oed }}$. Deformation parameters of soil by adding cement may bring an increase 2-3 times. This effect is linked to the initial soil moisture before stabilization; value $w_{\text {opt }}$ should not be exceeded by $5 \%$. In exceeding this moisture there is not expected a major stabilization effect.

\section{ACKNOWLEDGEMENT}

The paper is a part of results from a research project supported by the Slovak agency VEGA No. 1/0882/16 "Influence of boundary conditions to limit states of geotechnical structures".

\section{REFERENCES}

[1] STN 72 1001: Classification of soil and rock in engineering geology and geotechnics (in Slovak), 2010.

[2] P. Turček, M. Súlovská, Z. Štefunková. Evaluation of soil layers improving below the production hall (in Slovak). SvF STU Bratislava, 2016.

[3] P. Turček, M. Súlovská, Z. Štefunková. Experimental research of deformation properties of fine-grained soil situated in hall subgrade (in Slovak). SvF STU Bratislava, 2016.

[4] P. Turček, J. Frankovská, Súlovská. Geotechnical design according to Eurocodes (in Slovak). Engineering Advisory Centre of Slovak Chamber of Civil Engineers, 2010.

[5] EN 197-1: Cement. Part 1: Composition, specifications, and conformity criteria for common cements, 2012. 